\title{
Effect of Cinnamomum zeylanicumon on Spermatogenesis
}

\author{
Arash Khaki ${ }^{1, *}$ \\ ${ }^{1}$ Department of Pathology, Tabriz Branch, Islamic Azad University, Tabriz, Iran \\ *Corresponding Author: Arash Khaki, Department of Pathology, Tabriz Branch, Islamic Azad University, Tabriz, Iran. Tel: +98-9143138399, E-mail: arashkhaki@yahoo.com , Khaki@ \\ iaut.ac.ir
}

Received: March 1, 2014; Revised: May 25, 2014; Accepted: July 6, 2014

\begin{abstract}
Background: In modern countries today, herbal medicines are known to help in the treatment of various diseases, as rich sources of antioxidants and minerals.

Objectives: To study the effect of Cinnamomum zeylanicum (C. zeylanicum) on spermatogenesis in rats.

Materials and Methods: In this experimental study, Wistar male rats $(n=20)$ were divided into two groups, a control group $(n=10)$ and a Cinnamomum zeylanicum group $(\mathrm{n}=10)$. The subjects in the cinnamon group received $75 \mathrm{mg} / \mathrm{kg} / \mathrm{day}$ cinnamon by gavage for 28 days, while the controls received an equal volume of distilled water daily. Animals were kept in standardized conditions. On day 28 , a $5 \mathrm{~mL}$ blood sample from each rat was taken from tail area to measure testosterone, superoxide dismutase(SOD), catalase(CAT), glutathione peroxidase (GPX), and malondialdehyde (MDA) levels. Testes were collected and were then prepared for sperm analysis by the WHO method.

Results:Sperm quality parameters, total serum testosterone,SOD, CAT, and GPX levels were significantly increased in the cinnamon group in comparison to controls $(\mathrm{P}<0.05)$. Also, rats in the cinnamon group showed a significant decrease in the level of plasma MDA $(\mathrm{P}<0.05)$ in comparison to controls. There were no significant differences between the groups in testis weight $(\mathrm{P}>0.05)$.

Conclusions: The administration of $75 \mathrm{mg} / \mathrm{kg} /$ day cinnamon significantly increased the sperm population, motility and viability, which supports the theory that in mammalians, cinnamon has a beneficial effect on spermatogenesis.
\end{abstract}

Keywords:Catalase; Cinnamomum Zeylanicum; Spermatogenesis; Superoxide Dismutase; Testosterone

\section{Background}

Infertility is one of the most controversial health issues in medical sciences. Male factors, including hormonal problems, decreased sperm quality and quantity are the cause of $30 \%$ of cases reported of infertility. Several diseases, such as coronary heart diseases, diabetes mellitus and chronic liver diseases may interfere with the spermatogenesis process, and therefore sperm quality and quantity may be altered by these diseases (1). Antioxidants are regarded as significant agents, which contribute to the overall health of the organism. Polyphenols, as dietary antioxidants, are associated with redox activities and have beneficial effects on health (2). Oxidative stress is an important process that is involved in multiple conditions like infertility and inflammation (3). Therefore, these diseases are controlled in people receiving antioxidant supplements (2). Antioxidant enzymes, such as catalase (CAT), superoxide dismutase (SOD) and glutathione (GSH), have a significant role in establishing a balance between reactive oxygen species (ROS) and antioxidant levels in serum (4). The use of antioxidants may improve spermatozoa viability and longevity (4). In recent years, phytotherapy has been more common in Europe and the USA $(5,6)$. Cinnamon has been used to treat abdominal and chest pains, chronic diarrhea, hypertension, kidney disorders and rheuma- tism, in eastern and western folk medicine (7). Cinnamon could induce hepatoprotective and antioxidant effects in rats with impaired liver function by carbon tetrachloride $\left(\mathrm{CCl}_{4}\right)(6)$. Cinnamon extract, an antioxidant that is a rich source of polyphenolic compounds, plays a significant role in the modulation of oxidative stress in the obese people with impaired fasting glucose. Furthermore, it is also used as a remedy for reducing the risk of infertility, cardiovascular diseases related to inflammation and other complications related to oxidative stress (7).

\section{Objectives}

The aim of this study is to assess the effects of Cinnamomum zeylanicum (C. zeylanicum) as an antioxidant source on sperm quality parameters.

\section{Materials and Methods}

\subsection{Animals}

Twenty adult Wistar albino male rats, 8 weeks old, weighing $250 \pm 10 \mathrm{~g}$, were obtained from the animal facility of Pasteur Institute of Iran, Tehran, Iran. Male rats were housed in temperature controlled rooms $\left(25^{\circ} \mathrm{C}\right)$ 
with constant humidity (40-70\%) and 12 hours light/dark cycle, prior to be used in the experimental protocols. All animals were treated in accordance with the Principles of Laboratory Animal Care. The experimental protocol was approved by the Animal Ethical and Scientific Committee of Tabriz University of Medical Sciences, in accordance with the guide for the care and usage of laboratory animals prepared by Tabriz Medical University, Tabriz, Iran, with reference number: 9017. All rats were fed standard diet and water and the daily intake of water was monitored for each animal. Thereafter, the Wistar male rats ( $\mathrm{n}$ $=20$ ) were randomly divided into two groups, a control group $(n=10)$ and the cinnamon group $(n=10)$. The cinnamon group rats received $75 \mathrm{mg} / \mathrm{kg} /$ day of Cinnamon powder in distilled water by gavage method, during for 4 weeks, whereas the controls received an equal volume of distilled water daily. All the observation was performed by a single observer.

\subsection{Preparation of Cinnamon}

The C. zeylanicum was bought from a local market in the Istanbul province, Turkey. An amount of $100 \mathrm{~g}$ of C.zeylanicum were powdered in the Department of Pharmacognosy, Tabriz University of Medical Sciences, Tabriz, Iran. At a concentration of $75 \mathrm{mg} / \mathrm{kg}$, the C.zeylanicum was dispersed in $2 \mathrm{~mL}$ of distilled water and each rat received it daily, for 28 days.

\subsection{Qualitative Analysis}

The methanolic extract of cinnamon was subjected to phytochemical screening, to identify the chemical constituents. Thin-layer chromatography (TLC) was performed on silica gel GF254 with toluene/ethyl acetate (93:7). Detection of the spots by spraying vanillin-sulfuric acid revealed the presence of cinnamaldehyde as major grey-blue, zone at a retention factor $(\mathrm{RF})=0.5$ in this extract.

\subsection{Surgical Procedure}

For the collection of samples on day 28 , sodium pentobarbital (40 mg/kg) was administered intra peritoneal (IP) for anesthesia, and the peritoneal cavity was opened through a lower transverse abdominal incision. Thereafter, the epididymis was immediately removed in both cinnamon and control subjects. The weight of the epididymis in each group was registered. The animals were decapitated between 9:00 AM and 11:00 AM.

\subsection{Epididymis Sperm Count, Viability and Motility}

The cauda epididymis was cut and sperms were released into $2 \mathrm{~mL}$ of medium Ham's F-10 medium (Sigma, USA) containing $0.5 \%$ bovine serum albumin. After 5 minutes of incubation at $37^{\circ} \mathrm{C}$ (with $5 \% \mathrm{CO}_{2}$ ), the cauda epididymis sperm reserves were determined by using the standard hemocytometric method and sperm motility was analyzed with a microscope (Olympus IX70, Olympus Corp.,
Shinjuku, Tokyo, Japan) at 10X magnification and was reported as the mean of motile sperm according to the World Health Organization (WHO) method. The ocular of the microscope was equipped with (Sony DXC-107A CCD-IRIS Color Video Camera, Sony Corp., Minato, Tokyo, Japan) to record the images. In the end of the study, the tape was viewed by an investigator that was not a member of the study team, to avoid bias (7).

\subsection{Total Serum Testosterone Hormone Measure- ment}

Total serum concentration of testosterone was measured using a double-antibody radioimmunoassay (RIA) kit (Immunotech Laboratories Inc, Glendale CA, USA). The testosterone detection threshold per assay tube was $0.025 \mathrm{ng} / \mathrm{mL}$.

\subsection{Malondialdehyde Concentration Measure- ment in Serum}

Free radical damage was determined by specifically measuring malondialdehyde (MDA). The MDA, formed as an end-product of lipid peroxidation (LPO), was treated with thiobarbituric acid to generate a colored product measured at $532 \mathrm{~nm}$ (MDA detection kit, Nanjing Jiancheng Bioengineering Institute, Nanjing, China).

\subsection{Super Oxide Dismutase Activity Measurement in Serum}

The activity of SOD was measured by following the method of Beyer and Fridovich (8).

\subsection{Glutathione Peroxidase Activity Measurement in Serum}

The GSH peroxidase activity (GPX) activity was quantified by following the decrease in absorbance at $365 \mathrm{~nm}$ induced by $0.25 \mathrm{mM} \mathrm{H}_{2} \mathrm{O}_{2}$ in the presence of reduced GSH(10 mM), nicotinamide adenine dinucleotide phosphate (NADPH) (4 mM), and $1 \mathrm{U}$ enzymatic activity of GSH reductase $(G R)(9)$.

\subsection{Catalase Activity Measurement in Serum}

Serum CAT activity was determined according to the method of Beers and Sizer, as described by Usoh et al. (10), by measuring the decrease in absorbance at $240 \mathrm{~nm}$ due to the decomposition of $\mathrm{H}_{2} \mathrm{O}_{2}$ in a UV recording spectrophotometer. The reaction mixture $(3 \mathrm{~mL})$ contained 0.1 $\mathrm{mL}$ of serum in phosphate buffer (50 mM, pH 7.0) and $2.9 \mathrm{~mL}$ of $30 \mathrm{mM} \mathrm{H}_{2} \mathrm{O}_{2}$ in phosphate buffer ( $\mathrm{pH}$ 7.0). An extinction coefficient for $\mathrm{H}_{2} \mathrm{O}_{2} \mathrm{~cm}^{-1}$ was used for calculation. The specific activity of CAT was expressed as moles of $\mathrm{H}_{2}$ reduced per minute per $\mathrm{mg}$ protein, at $240 \mathrm{~nm}$. An amount of $40.0 \mathrm{M}^{-1} \mathrm{~cm}^{-1}$ was used for calculation. The specific activity of CAT was expressed as moles of $\mathrm{H}_{2} \mathrm{O}_{2}$ reduced per minute per mg protein. 


\subsection{Statistical Analysis}

All of the variables naturally follow normal distribution. For selecting the sample size, as calculated statistically with Minitab statistical software, version 16 (Minitab Inc., Pennsylvania State University, Pennsylvania, USA) considering an expected power of 0.9, standard deviation of 1.5 and differences of 2 , the indicated size was 9 . However, we considerers $n=10$ for the sample size. Statistical analysis was done by using the T-tests on the SPSS analytical software, version 17 (SPSS Inc., Chicago, ILL, USA) to compare the data from the control group with the data from the experimental group. The results were expressed as Mean \pm SD. A P $<0.05$ was considered significant.

\section{Results}

\subsection{Weight of Epididymis}

According to the results presented in Table 1, there were no significant differences in epididymis weights between the groups.

C. zeylanicum, Cynnamomum zeylanicum; Hb, hemoglobin.

\subsection{Results of Sperm Motility, Viability and Count}

Administration of $75 \mathrm{mg} / \mathrm{kg}$ C. zeylanicum for 28 days significantly increased sperm concentration, motility and viability in the experimental group compared to controls ( $\mathrm{P}$ $=0.21$. The results were $63.3 \pm 0.95,77 \pm 1.26$ and $50.20 \% \pm$ $7.43 \%$, respectively, in the cinnamon group, and $33 \pm 9.49,58$ \pm 8.06 and $38.40 \pm 4.07$, respectively, for controls (Table 1 ).

\subsection{Results of Serum Total Testosterone}

Administration of $75 \mathrm{mg} / \mathrm{kg}$ cinnamon for 28 days sig- nificantly increased serum total testosterone in treated animals compared to controls $(\mathrm{P}=0.21)$. The results were $3.87 \pm 0.70$ and $1.65 \pm 1.74$, for the cinnamon group and controls, respectively (Table 1 ).

\subsection{Results of Malondialdehyde Concentration in Serum}

Administration of $75 \mathrm{mg} / \mathrm{kg}$ cinnamon for 28 days significantly decreased MDA concentration in the experimental group compared to controls $(P=0.21)$, with $2.65 \pm 1.74$ and5.05 \pm 1.74 , respectively (Table 1 ).

\subsection{Results of Super Oxide Dismutase Concentra- tion in Serum}

Administration of $75 \mathrm{mg} / \mathrm{kg} \mathrm{C}$. zeylanicum for 28 days significantly increased SOD concentration in the experimental group compared to the control group ( $\mathrm{P}=$ 0.21 , with the results of $1247 \pm 2.62$ and $1000 \pm 1.74$, respectively (Table 1).

\subsection{Results of Glutathione Peroxidase Activity in Serum}

Administration of $75 \mathrm{mg} / \mathrm{kg}$ cinnamon for 28 days significantly increased GPX concentration in the experimental group (138.4 \pm 8.54$)$ compared to the control group (125 \pm 8.54 $)($ P value $=0.21)($ Table 1$)$.

\subsection{Results of Catalase Activity in Serum}

Administration of $75 \mathrm{mg} / \mathrm{kg}$ C. zeylanicumfor 28 days significantly increased CAT concentration in the experimental group (336.4 \pm 9.64$)$ compared to the control group $(306.4 \pm 12.81)($ P value $=0.21)($ Table 1$)$.

Table 1. The Effect of the $75 \mathrm{mg} / \mathrm{kg} /$ rat Cinnamomum zeylanicum on Sperm Quality Parameters, Malondialdehyde, Super Oxide Dismutase, Glutathione Peroxidase, Catalase, Testosterone and Epididymis Weight of the Experimental Group in Comparison to the Con$\operatorname{trol} \operatorname{Group}(\mathrm{n}=10)^{\mathrm{a}}$

\begin{tabular}{|c|c|c|c|}
\hline Samples Groups & Control & C.zeylanicum b & PValue \\
\hline Epididymis, $\mathrm{g}$ & $1 \pm 1.04$ & $1 \pm 1.74$ & 0.081 \\
\hline $\begin{array}{l}\text { Sperm concentration (total } \\
\text { count), No of sperm/rat } 10^{6}\end{array}$ & $38.40 \pm 4.07$ & $50.20 \pm 7.43$ & 0.03 \\
\hline Motility, $\%$ & $33 \pm 9.49$ & $63.3 \pm 0.95$ & 0.027 \\
\hline Viability, $\%$ & $58 \pm 8.06$ & $77 \pm 1.26$ & 0.019 \\
\hline Testosterone, $\mathrm{ng} / \mathrm{mL}$ & $1.65 \pm 1.74$ & $3.87 \pm 0.70$ & 0.0001 \\
\hline Malondialdehyde & $5.05 \pm 1.74$ & $2.65 \pm 1.74$ & 0.021 \\
\hline Super oxide dismutase, u/g Hb & $1000 \pm 1.74$ & $1247 \pm 2.12$ & 0.041 \\
\hline Glutathione peroxidase, u/mg Hb & $125 \pm 8.54$ & $138.4 \pm 8.54$ & 0.071 \\
\hline Catalase, u/mg Hb & $306.4 \pm 12.81$ & $336.4 \pm 9.64$ & 0.068 \\
\hline
\end{tabular}

a Data are presented as Mean \pm SD

$\mathrm{b}_{75 \mathrm{mg} / \mathrm{kg} \text {-per day. }}$ 


\section{Discussion}

Although the pathophysiology of male infertility has always been unclear, evidence shows that antioxidative changes are probably responsible for the abnormal spermatozoa function and fertilization capacity (11). The ROS, a class of free radicals with unpaired electrons, are byproducts of metabolic and pathophysiologic processes (12). Most probably, ROS impair spermatozoa by peroxidation of membranous lipids and fragmentation of nucleic acids, leading to spermatozoa dysfunction (13). Seminal plasma, which is a rich source of antioxidants, protects sperm against oxidative stress by enzymes with powerful antioxidant activity such as CAT, SOD and GPX. According to previous studies, a decreased level of antioxidants in seminal plasma of infertile men is correlated with the elevated level of MDA, which results in important LPO. The GPX is an important antioxidant, which protects the epididymis and the ejaculated spermatozoa (14). Nowadays, in multiple countries, plants are used in the treatment of multiple diseases because of the richness of antioxidants, which is a characteristic phenomenon in traditional medicine (15). Antioxidants neutralize the oxidation process by biding to free radicals, chelating catalytic metals and acting as oxygen scavengers (16). Moreover, ancient traditional Persian books expressed the positive effects of herbal medicine on the treatment of different diseases, especially diabetes mellitus. C. zeylanicum has $65.3 \%$ antioxidant activity and also a very strong free radical scavenging activity. According to in-vivo and in-vitro studies, $C$. zeylanicum has antimicrobial, antiparasitic, antioxidant and free radical scavenging properties. Furthermore, it could lower serum cholesterol, blood pressure and blood glucose in diabetic people (17).

Several studies have reported a protective effect of dietary antioxidants and vitamins A, B, C, and E on sperm DNA against free radicals and improvement of the bloodtestis barrier stability. As the use of cinnamon leads to the elevation of testosterone secretion, it could enhance its fertility properties $(18,19)$. This study showed that using $75 \mathrm{mg} / \mathrm{kg}$ of C. zeylanicum as an antioxidant in food increased SOD, GPX, and CAT, leading to the elimination of ROS. Therefore, sperm cells are protected from oxidation. Yuce et al. in 2013, reported that C. zeylanicum bark oil could modify changes induced by administration of $\mathrm{CCl}_{4}$. Therefore, C. zeylanicum increases the weights of testis and epididymis, while increasing sperm quality, as well as decreasing LPO level and the apoptotic index (20). This study confirms the previous studies in this field $(12,21)$. Spermatogenesis and male fertility are dependent upon the presence of testosterone in the testis. A reduction of serum testosterone is probably associated with alterations in body composition, diminished energy, muscle strength, and sexual function. Therefore, androgens and partial androgens are essential for male fertility and the maintenance of spermatogenesis (22), especially in various disease which exacerbate the decline in testoster- one. This study also demonstrated the effect of cinnamon in the improvement of serum total testosterone.

According to the results in the experimental group, cinnamon could increase sperm quality parameters such as population, viability and motility. Herbal antioxidants eliminate and suppress ROS formation, and the reduction of ROS is a crucial factor in the production of sperm cells, $(18,23)$ and optimization of the fertility rate. More research seems to be necessary to confirm the pharmacological and toxicological effects of this medical herb on body tissues.

Results demonstrated that the GPX, CAT and SOD contained by C. zeylanicum could increase serum antioxidant levels male rats. Therefore, it has the potential to restore fertility and normal spermatogenesis, and to improve testosterone level and sperm quality parameters, such as population, viability and motility, while in the meantime decreasing the MDA level. Therefore, this study and the previous ones confirm the positive effects of C. zeylanicum on infertility and sperm quality parameters $(1,17-19,24)$.

\section{Funding/Support}

This research was financially supported by Women's Reproductive Health Research Center, Tabriz University of Medical Sciences, Tabriz, Iran.

\section{References}

1. Shalaby MA, Mouneir SM. Effect of zingiber officinale roots and cinnamon zeylanicum bark on fertility of male diabetic rats. Glob Veter. 2010;5(6):341-7.

2. Scalbert A, Manach C, Morand C, Remesy C, Jimenez L. Dietary polyphenols and the prevention of diseases. Crit Rev Food Sci Nutr. 2005;45(4):287-306

3. Dragsted LO. Antioxidant actions of polyphenols in humans. Int J Vitam Nutr Res. 2003;73(2):112-9.

4. Khaki A, Fathiazad F, Nouri M, Khaki AA, Khamenehi HJ, Hamadeh M. Evaluation of androgenic activity of allium cepa on spermatogenesis in the rat. Folia Morphol (Warsz). 2009;68(1):45-51.

5. Drobiova H, Thomson M, Al-Qattan K, Peltonen-Shalaby R, AlAmin Z, Ali M. Garlic increases antioxidant levels in diabetic and hypertensive rats determined by a modified peroxidase method. Evid Based Complement Alternat Med. 2011;2011:703049.

6. Bakhsha F, Mazandarani M, Aryaei M, Jafari SY, Bayate H. Phytochemical and Anti-oxidant Activity of Lavandula Angustifolia Mill. Essential oil on Preoperative Anxiety in Patients undergoing Diagnostic Curettage. Int J Women's Health Reprod Sci. 2014 ;2(4):268-271.

7. Shobana S, Naidu KA. Antioxidant activity of selected Indian spices. Prostaglandins Leukot Essent Fatty Acids. 2000;62(2):107-10.

8. Beyer WJ, Fridovich I. Assaying for superoxide dismutase activity: some large consequences of minor changes in conditions. Anal Biochem. 1987;161(2):559-66.

9. Yoshikawa T, Naito Y, Kishi A, Tomii T, Kaneko T, Iinuma S, et al. Role of active oxygen, lipid peroxidation, and antioxidants in the pathogenesis of gastric mucosal injury induced by indomethacin in rats. Gut. 1993;34(6):732-7.

10. Usoh IF, Akpan EJ, Etim EO, Farombi EO. Antioxidant Actions of Dried Flower Extracts of Hibiscus sabdariffa L. On Sodium Arsenite - Induced Oxidative Stress in Rats. Pak J Nutr. 2005;4(3):135-41.

11. Akinloye O, Arowojolu AO, Shittu OB, Adejuwon CA, Osotimehin B. Selenium status of idiopathic infertile Nigerian males. Biol Trace Elem Res. 2005;104(1):9-18.

12. Agarwal A, Sharma RK, Nallella KP, Thomas AJ, Alvarez JG, Sikka 
SC. Reactive oxygen species as an independent marker of male factor infertility. Fertil Steril. 2006;86(4):878-85.

13. Nabil H, Moemen LA, Elela MHA. Studying the levels of malondialdehyde and antioxidant parameters in normal and abnormal human seminal plasma. Aust J Basic Appl Sci. 2008;2(3):773-8.

14. Sunde RA. The biochemistry of selenoproteins. JAm Oil Chem Soc. 1984;61(12):1891-900.

15. Virgili F, Scaccini C, Packer L, Rimbach G. Cardiovascular disease and nutritional phenolics. Antioxidants in Food.. Cambridge: Woodhead Publishing Ltd.; 2001. pp. 87-99.

16. Kelen M, Tepe B. Screening of antioxidative properties and total phenolic compounds of various extracts of three different seed of grape varieties (Vitis vinifera L.) from Turkish flora. Pak J Biol Sci. 2007;10(3):403-8.

17. Ranasinghe P, Pigera S, Premakumara GA, Galappaththy P, Constantine GR, Katulanda P. Medicinal properties of 'true' cinnamon (Cinnamomum zeylanicum): a systematic review. BMC Complement Altern Med. 2013;13:275.

18. Khaki A, Fathiazad F, Nouri M, Khaki A, Maleki NA, Khamnei $\mathrm{HJ}$, et al. Beneficial effects of quercetin on sperm parameters in streptozotocin-induced diabetic male rats. Phytother Res.
2010;24(9):1285-91.

19. Jedlinska-Krakowska M, Bomba G, Jakubowski K, Rotkiewicz T, Jana B, Penkowski A. Impact of oxidative stress and supplementation with vitamins $\mathrm{E}$ and $\mathrm{C}$ on testes morphology in rats. J Reprod Dev. 2006;52(2):203-9.

20. Yuce A, Turk G, Ceribasi S, Guvenc M, Ciftci M, Sonmez M, et al. Effectiveness of cinnamon (Cinnamomum zeylanicum) bark oil in the prevention of carbon tetrachloride-induced damages on the male reproductive system. Andrologia. 2014;46(3):263-72.

21. Yen GC, Duh PD. Antioxidative properties of methanolic extracts from peanut hulls. JAm Oil Chem Soc .1993;70(4):383-6.

22. Vahdani V, Khaki A. Effect of Allium cepa Seed Extract on Serum Testosterone in Rats. Crescent J Med Biol Sci. 2014; 1(3):110-112.

23. Henkel R. The impact of oxidants on sperm function. Andrologia 2005;37(6):205-6.

24. World Health Organization.. Laboratory Manual for the Examination of Human Semen and Semen-Cervical Mucus Interaction. 4 edNewYork: Cambridge University Press; 1999. 